\title{
Invariance of inference time when information was presented in different linguistic formats*
}

\author{
DAVID R. W. KING and JAMES G. GREENO \\ University of Michigan, Ann Arbor, Michigan 48104
}

\begin{abstract}
Ss read paragraphs varying in syntactic complexity, contiguity of information that was conceptually related, and amount of information relating to quantitative variables. Paragraphs were presented too briefly to allow full reading in many cases. In questions requiring use of the quantitative information, proportion of correct responses was influenced by syntax, contiguity, and number of variables from the paragraph. However, neither syntax nor contiguity influenced latency of correct answers, while number of variables, a factor affecting complexity of the process of answering, did influence correct response latency. The findings confirm and extend earlier results by Kintsch and Monk (1972) and give further support to the proposition that assimilation of information in linguistic input involves storing the semantic content of the message.
\end{abstract}

Evidence is accumulating for the idea that, when $S$ reads or hears a message, the result is construction of a cognitive structure representing the meaning of the message. In the present experiment we used a procedure introduced by Kintsch and Monk (1972) to investigate this process. Kintsch and Monk found that syntactic variables affected the time it took Ss to read paragraphs and, when only limited time was given, syntactic complexity decreased the number of correct answers given to questions requiring inferences based on the paragraphs. But in cases where correct inferences were made, the time needed to make an inference was not longer when the paragraph had been given in complex form than when it had been simple. The most straightforward interpretation is that the representation of semantic information in the paragraph was not affected by the syntactic format, although awkward syntax made it harder to achieve that relatively invariant structure. We used somewhat different kinds of materials from any of those used by Kintsch and Monk and, in addition to varying syntactic variables, we also varied the contiguity of related items of information. Results of Bransford and Franks (1971) suggest that, in S's cognitive representation, those parts of a message that are conceptually related are organized together, whether or not they occurred contiguously in the message.

\section{METHOD}

\section{Subjects and Design}

Thirty-six Ss from the Human Performance Center S pool participated in the study for payment of $\$ 1.50$.

The main data came from 12 items seen by each $\mathrm{S}$ in which $\mathrm{S}$ was asked to judge whether information in the paragraph made it possible to compute the value of a specified variable. Each S's 12 computability items represented one-half of a replication of a 2 by 2 by 3 by 2 factorial design. The first factor was syntactic

*This research was supported by the National Science Foundation under Grant GB 31045. complexity, with paragraphs written in either simple or complex form. The second factor was contiguity of information, with information about the quantitative variables involved in possible computation presented either contiguously in the paragraphs or separated by other information. The third factor was complexity of the inference needed to answer the question, corresponding to the number of variables given values in the paragraphs; inferences about computability were related to paragraphs having two, three, or four quantitative variables specified. The fourth factor was the correct response; items either were or were not computable, so the correct answer was either "yes" or "no."

\section{Materials}

Ss initially memorized four equations involving facts about driving:

$$
\begin{aligned}
\text { DISTANCE } & =\text { AVERAGE SPEED } \times \text { DRIVING TIME } \\
\text { DISTANCE } & =\text { MILEAGE } \times \text { FUEL USED } \\
\text { AVERAGE SPEED } & =\text { AVERAGE FORCE } / \text { WEIGHT } \\
\text { DRIVING TIME } & =\text { DURATION }- \text { STOP TIME }
\end{aligned}
$$

During the main part of the experiment, each S saw 18 paragraphs, each followed by a question that could be answered "yes" or "no." Each paragraph told a story about a driving trip. The paragraph contained some quantitative information and some descriptive information. The quantitative information consisted of the values of variables in the equations, and the number of variables was two, three, or four, depending on the paragraph. Enough descriptive information was given so that a total of six facts were given in the paragraph. Every paragraph contained the name of the person taking the trip and the city that was the person's destination. In addition, paragraphs having three quantitative facts contained the reason for taking the trip Paragraphs having two quantitative facts contained the reason for the trip and a statement about something the person took along on the trip. All paragraphs were approximately 49 words long, including punctuation.

Define a problem type as a set of paragraphs having the same number of quantitative facts (two, three, or four) and the same correct answer ("yes" or "no"). Thus, there were six problem types. The 18 paragraphs seen by each $\mathrm{S}$ included three of each problem type.

Four different formats were used in presenting the paragraphs. Syntactic complexity was varied, with simple paragraphs consisting of five direct, declarative sentences, and with complex paragraphs each being a single long, complicated sentence in which many syntactic transformations, such as active to passive 
Table 1

Proportions and Mean Latency (Seconds) of Correct Responses

\begin{tabular}{llcc}
\hline Syntax & Contiguity & $\begin{array}{c}\text { Pro- } \\
\text { portion } \\
\text { Correct }\end{array}$ & $\begin{array}{c}\text { Latency of } \\
\text { Correct } \\
\text { Responses }\end{array}$ \\
\hline Simple & Contiguous & .77 & 10.4 \\
Simple & Noncontiguous & .68 & 10.1 \\
Complex & Contiguous & .73 & 9.5 \\
Complex & Noncontiguous & .60 & 10.5 \\
\hline
\end{tabular}

and embedding of clauses, were made that did not change the factual content of the story. Contiguity was varied by presenting the quantitative facts either contiguously, at the beginning or the end of the paragraph, or noncontiguously, interspersed with filler information. Let $Q$ stand for a quantitative fact and $F$ stand for a descriptive fact used as filler information in the paragraph. With two noncontiguous quantitative facts, the sequence was QFFFFQ. When there were three quantitative facts, the noncontiguous sequence was either QFQFFQ or QFFQFQ. When there were four quantitative facts, the noncontiguous sequence was one of the following: QQFFQQ, QFQFQQ, or QQFQFQ. Further, when two variables from a single equation were used, they were spaced as widely as possible in the noncontiguous paragraphs but given successively in contiguous paragraphs.

To illustrate the format manipulations, one of the stories is given below in all four formats.

\section{Simple, Contiguous}

Greg drove all the way to Detroit. He went there to look for a job. He brought with him a letter of recommendation. He maintained an average driving speed of 70 miles per hour. His car used 35 gallons of fuel on the way.

\section{Simple, Noncontiguous}

Greg maintained an average driving speed of 70 miles per hour. He drove all the way to Detroit. He went there to look for a job. He brought with him a letter of recommendation. His car used 35 gallons of fuel on the way.

\section{Complex, Contiguous}

In Greg's driving all the way to Detroit, where he went in order to look for a job bringing with him a letter of recommendation, an average speed of 70 miles per hour was maintained while 35 gallons of fuel were used by his car.

\section{Complex, Noncontiguous}

An average driving speed was maintained of 70 miles per hour in Greg's driving all the way to Detroit where he went in order to look for a job, bringing with him a letter of recommendation, while 35 gallons of fuel were used by his car.

Following each paragraph, $S$ saw either a question about computability (in 12 cases) or a question about one of the nonquantitative facts in the paragraph (in six cases). The computability questions were all of the form, "From the information given, can you compute ..."? The other questions were answered by "yes" or "no;" for example, "Did he take the trip to visit his grandmother"?

\section{Procedure}

Ss were given $5 \mathrm{~min}$ to memorize the driving story equations. As a test of their knowledge of the equations, they were required to answer several computability judgment problems, such as: "If you knew values for driving time and distance, could you compute average speed"?

Ss answered six such problems, one of each type. Following a distracting task (writing the alphabet backward), they attempted to recall the equations in the exact words in which they were presented. Ss who made any errors on either task were required to study the equations again for $2 \mathrm{~min}$, after which the same problems were repeated, along with other administered verbally by E. Several Ss who failed twice to answer the problems correctly were discarded.

After demonstrating their mastery of the equations, Ss were seated in front of a tachistoscope, on which were presented the series of paragraphs and questions. During two warm-up trials, Ss were allowed to read the paragraph for as long as they wanted; following their signal that they were finished reading the paragraph, the question was presented. Pilot Ss who had been run previously under similar conditions of self-controlled reading time took an average of approximately $45 \mathrm{sec}$ to read the paragraphs used in the study. Following the example of Kintsch and Monk (1972) and guided by some preliminary observations, we set the reading time for experimental trials at $15 \mathrm{sec}$, one-third of the average unpaced reading time. The paragraph was followed immediately by the question, which remained on the screen for $20 \mathrm{sec}$, after which a blank screen stayed illuminated for a further $20 \mathrm{sec}$ to give $\mathrm{S}$ ample time to respond.

As soon as the light illuminating the screen went out, $E$ pushed a button to start the next trial. Accordingly, Ss were informed that the offset of this light signaled the beginning of the next trial. Onset of the question started a response timer, which stopped when S pushed either the "yes" or "no" button.

Instructions to Ss emphasized accuracy; they were told to answer as accurately as they could but, within that constraint, to answer as quickly as possible. It was also emphasized that they should not skip any part of the paragraph but read it as completely and thoroughly as possible during the $15 \mathrm{sec}$. Feedback was given after the two warm-up trials but not after the experimental trials. Responses and times were recorded manually by $\mathrm{E}$.

\section{RESULTS}

The major findings involve effects of the manipulations of format. Table 1 shows the proportions of correct response and the mean latency for correct responses in the four kinds of format. These statistics are averaged across response type and number of given variables.

For statistical analysis, data from the 36 Ss were combined to form 18 replications of the 2 by 2 by 3 by 2 design, with two Ss in each replication. Regarding the proportions of correct response, contrasts were evaluated using the interaction of Replications by Effects as error terms. The error terms varied between .126 and .175 , indicating that the standard errors of the means shown in Table 1 were on the order of .034 to .040 when replications are included in the sources of random variation. Ninety-five percent confidence limits for orthogonal contrasts were as follows: effect of syntactic complexity, $.060 \pm .072$; effect of contiguity, $.106 \pm .085$; interaction, $.023 \pm .072$. The effect of syntactic complexity was similar in magnitude to that obtained in Kintsch and Monk's experiments. We conclude that the manipulations of syntax and contiguity had the effects on difficulty of comprehension that were expected. 
In analyzing latencies of correct responses, too many data were missing to permit estimation of interaction mean squares, so contrasts were evaluated using an error term that omitted replications as a source of variance. The estimated mean square error was $46.17 \mathrm{sec}^{2}$, indicating that the standard error of the means reported in Table 1 was about $0.65 \mathrm{sec}$. None of the contrasts examined approached significance; with 95\% confidence: effect of syntactic complexity, $0.2 \pm 1.4 \mathrm{sec}$; effect of contiguity, $-0.4 \pm 1.4 \mathrm{sec}$; interaction, $0.6 \pm 1.4 \mathrm{sec}$. Note that the use of the residual error term rather than an interaction term probably underestimates the error term for these contrasts; thus, the decision that these manipulations were ineffective is a conservative one.

While linguistic format had little or no effect on the latency of correct responses, correct response latency was a reasonably sensitive index of experimental variables that affected the difficulty of inferences. Table 2 shows the mean latencies for correct responses depending on the number of quantitative variables in the paragraph and the correct response for the question. A larger number of given variables makes a question harder because more formulas have to be retrieved from memory to make the decision about computability. Negative items are not necessarily harder than positive items, but it is not unusual to find them so in research of this general kind (for example, see Collins \& Quillian, 1972). Significant main effects were obtained for both number of given variables $[F(2,278)=13.54, p<.01]$ and correct response $[F(1,278)=6.59, p<.025]$. The number of given variables also influenced the proportions of correct responses given: .83 of the two-variable problems, .62 of the three-variable problems, and .63 of the four-variable problems were given correctly, and the effect was reliable $[F(2,34)=16.6, p<.01]$. Whether the correct response was "yes" or "no" apparently did not influence proportion of correct response: 70 of the positive items and .69 of the negative items were answered correctly.

Table 2

\begin{tabular}{cccc} 
Mean & \multicolumn{2}{c}{$\begin{array}{c}\text { Table } 2 \\
\text { (Seconds) }\end{array}$ of Correct Responses } \\
\hline $\begin{array}{c}\text { Correct } \\
\text { Response }\end{array}$ & \multicolumn{2}{c}{ Number of Given Variables } \\
\hline Yes & 2 & 3 & 4 \\
No & 6.2 & 10.3 & 10.9 \\
\hline
\end{tabular}

\section{DISCUSSION}

The results reported here are generally confirming of recent findings and theoretical developments in the psychology of comprehension. We repeated Kintsch and Monk's (1972) result that time to make inferences is independent of the syntactic complexity of the input. We add the finding that independence also holds over variation in the contiguity of information that is closely related in conceptual meaning. If syntax or contiguity affected the form in which $S$ stored information in memory, it might be expected that inference time would be influenced. Since time for correct inferences appears to be independent of the format, it seems reasonable to conclude that the information stored in memory by $\mathrm{S}$ while reading the paragraphs consisted of the semantic contents of the paragraphs, since these were invariant across formats. The new finding involving contiguity in our study can be interpreted as further empirical support for Bransford and Franks's (1971) conclusion that, in assimilating a series of propositions, Ss form cognitive structures representing coherent ideas, and when a new proposition is added, it is located in the structure in a way that connects it to the other propositions whose meanings are related to it most closely. At a more general level, our findings appear to give further support to the proposition given early support by Sachs (1967) that, when we assimilate information by way of linguistic inputs, we build a cognitive structure in memory corresponding to the semantic and conceptual relations given in the message.

\section{REFERENCES}

Bransford, J. D., \& Franks, J. J. The abstraction of linguistic ideas. Cognitive Psychology, 1971, 2, 331-350.

Collins, A. M., \& Quillian, M. R. Experiments on semantic memory and language comprehension. In L. W. Gregg (Ed.), Cognition in learning and memory. New York: Wiley, 1972. Pp. 117-138.

Kintsch, W., \& Monk, D. Storage of complex information in memory: Some implications of the speed with which inferences can be made. Journal of Experimental Psychology, $1972,94,25-32$.

Sachs, J. Recognition memory for syntactic and semantic aspects of connected discourse. Perception \& Psychophysics, 1967, 2, $437-442$.

(Received for publication August 10, 1973; accepted August 20, 1973.) 